\title{
Improvement Concrete Mechanical Properties Using Static Magnetic Field Treatment
}

\author{
D.O.I - 10.51201/Jusst12681 \\ http://doi.org/10.51201/Jusst12681 \\ *Ikhlas S. SHEET ${ }^{1}$ \\ ${ }^{1}$ Northern Technical University, Mosul Technical Institute, Mosul 41002, IQ
}

\begin{abstract}
In the current study, a new technology of magnetized concrete prepared using static magnetic field treatment is investigated. Methodology of the current proposal is to manipulate the placing process of the fresh concrete samples, while maintaining the same materials with the same configurations. The purpose of this study is to determine the effect of different magnetic treatments to the fresh and hard concrete characteristics. Five set of samples are planned, one set using traditional process without magnetic treatment, while the other four sets are treated with 0.04, 0.08, 0.12 and $0.15 T$ (Tesla), respectively. The results showed that directly applying the magnetic field on concrete increases the compressive strength about (3-15\%) and it simultaneously improves the flow capacity (workability) for the fresh concrete corresponding to some certain treatment ranges. Unlikely, the study showed that the magnetic treatments could be detrimental for some other range of treatments especially at long-term performance. The results of this study could be a first step towards devolving new generation of smart structures through application of magnetic field treatment to the fresh concrete.
\end{abstract}

\section{Keywords: Magnetization of fresh concrete, Mechanical properties, Magnetic}

\section{treatment, and workability.}

\section{Introduction}

With the advancement of technology and increased field application of concrete and mortars the strength, workability, durability and other characteristics of ordinary concrete are continually undergoing modifications to make concrete more suitable for any situation $[1,2]$. The usage of magnetized water while mixing concrete will increase compressive strength, also there will be a higher workability for the same water to cement ratio. Many researchers proved that the scale formation is greatly reduced if the water passes through an intense magnetic flux which in turn changes the physical structure of water molecules and softens the hard water. Ahmed, 2009, [1] conducted an experimental investigation to study the effects of using magnetic water on engineering properties of concrete. The study explains elaborately the method and the process of magnetic water production for different flow speeds through different magnetic strengths. The study became a guidelines for many researchers used to conduct qualitative studies with regard of magnetic treatments.

A number of researches have been conducted to improve concrete mechanical properties, of which the compressive strength is the most significant, through magnetic treatment of water $[3,4,5]$. Other researchers produced magnetized water using various techniques [6-10]. In general they concluded that, the uses of magnetized water can improve the workability and 
increas the compressive strength by 10 to $25 \%$ and a greater increase in compressive strength is achieved when magnetic strength of treated water is 0.8 and $1.2 \mathrm{~T}$.

Iman et al. 2017, [11] improved flexural capacity of reinforced concrete members, using alternating magnetic field and alternating current electricity of different intensities. The study showed that the structural properties such as load-bearing capacity, deflection, bending stiffness, and ductility during the loading history were affected corresponding to the different magnetic field treatments.

Recently Khamees et al. 2020, [12] investigated effects of using magnetic water in concrete on compressive strength, workability and required cement content and they discovered that the maximum enhancement of concrete compressive strength was obtained at the maximum magnetic field intensity used, which was $1.3 \mathrm{~T}$. With the increase of using magnetized water in concrete, it is essentially required to provide, a simple, easy and applicable way to make it readily available to be used in concrete casting process. Since, the way of producing magnetized water is normally sensitive for water flow speed and magnetic field density. Moreover, it is uncertain that magnetized water can be stored. Therefore, in the current study a new technology for magnetizing the fresh concrete using different magnetic flux density is investigated. Methodology of the current proposal is to introduce a "magnetic treatment unit" prior to pouring the fresh concrete. Five set of samples are planned one batch using traditional process without magnetic treatment, while the other four batches are treated with $0.04,0.08$, 0.12 and $0.15 \mathrm{~T}$.

Almost all the experimental results have shown an increase in strength and workability of the concrete, the aim of this study is to quantify the optimal treatment level for fresh concrete to be recommended in concrete preparing process and specify the other negative consequences of the treatment to the fresh concrete.

\section{Research Significance}

Researchers are interested in the form of promoting concrete and concrete structures through product developments and improved efficiency. However, the effect of directly applying the magnetic field to fresh concrete on their properties have not yet been fully addressed (previous studies were focused on liquid treatments "magnetic water"). High magnetic flux density (>0.08 Tesla) is often used. Hence, this paper reports on an experimental study that aims to give engineers more confidence in the use of magnetic field treatment (mix treatment) in concrete production.

\section{Principles of Magnetic Treatment for Fresh Concrete (MTFC)}

When an electric current flows through a wire, a magnetic field is produced around the wire. The magnitude and direction of the field depends on the cross section of the wire, the direction and magnitude of the current through the wire. If the wire is wrapped into a loop, the field near the center of the loop is perpendicular to the plane of the loop. When a current flows in the solenoid coil, a magnetic field is produced, which is the result of Ampere's Law $[13,14]$. The right hand rule determines the direction of the magnetic field inside the pipe. The strength of the magnetic field is proportional to the product of the current, $=\mathbf{I}^{\varsigma}$, and the number of turns of the coil in the unit length, $=\mathbf{n}^{\prime}(\mathbf{N} / \mathbf{L})$ as:

$$
B=\mu_{0} \times n \times I
$$

Where: $\boldsymbol{\mu}_{\mathbf{0}}$ is the magnetic constant also known as vacuum permeability or permeability of free space, which is equal $4 \pi \times 10^{-7}$ and its unit of Newton per square ampere ${ }^{2}{ }^{26}$. The magnetic field force is also known as lines of magnetic flux or magnetic field lines. The unit 
of flux density is taken as the density of a magnetic field or magnetic flux density $\mathrm{B}^{\text {' }}$ and the unit termed as _Tesla' or Weber per meter square, $=\mathrm{Wb} / \mathrm{m}^{26}$.

Magnetic field lines do not go randomly. Field lines are normally useful for visualizing vector fields. These are not physical, they are actually present at specific locations, and the direction is a convention. The field lines are taken to direct away from the North-pole and towards South -pole. Figure (1) shows the schematic diagram of the circuit used in the current study to generate the magnetic field, lines from North and South poles illustrate the static magnetic field that generated when the current 'I' flows in the coil.

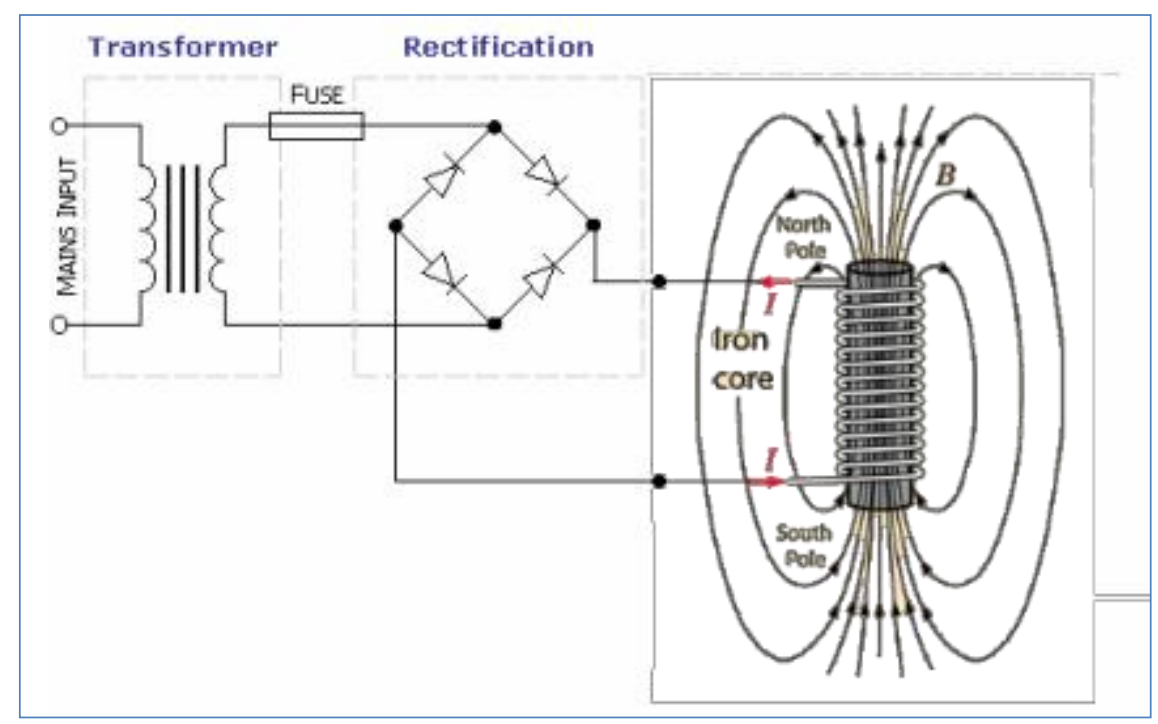

Figuer (1): Used circuit to produce static magnetic field.

Figure (2) shows the developed magnetic field generator used in to treat the fresh concrete prior to placing in the molds. The device was developed in such a way to produce various magnetic flux intensities (B) due to the changes in the number of roles $(\mathrm{N})$ and electric current (I), then calculate the magnetic flux from Eq.(1). In the current study the fresh concrete is treated in the device core (diameter $50 \mathrm{~mm}$, length $300 \mathrm{~mm}$ ).

There are three main factors that determine the magnetic properties of a material. The most basic factor is (i) the configuration of the electrons in the material's atoms; At the next level (ii) the ability of the atoms or molecules in the material to align magnetically (this is an important parameter that determines whether the material responds to a magnetic field); the final factor is (iii) the alignment of domains or sections in a solid object. The alignment is of high importance in the magnetic properties of materials, Liquids and gases. Basic fresh concrete components are typically non-magnetic materials because their molecules aren't held in place as they are in magnetic materials, as an exception the alignment of the ion charge can be affected at the surface of the particles, as shown in Figure (3). The positive and negative charges will be separated under the influence of a magnetic field; the molecules are aligned in accordance with the direction of the magnetic field. Figure (3) illustrates the resulting alignment at the surface of the fresh concrete components, the molecules are in an orderly arrangement, causing the particles to coagulate and aggregate In addition, the number of dipoles pointing in the direction of the field increases with increasing field strength. 


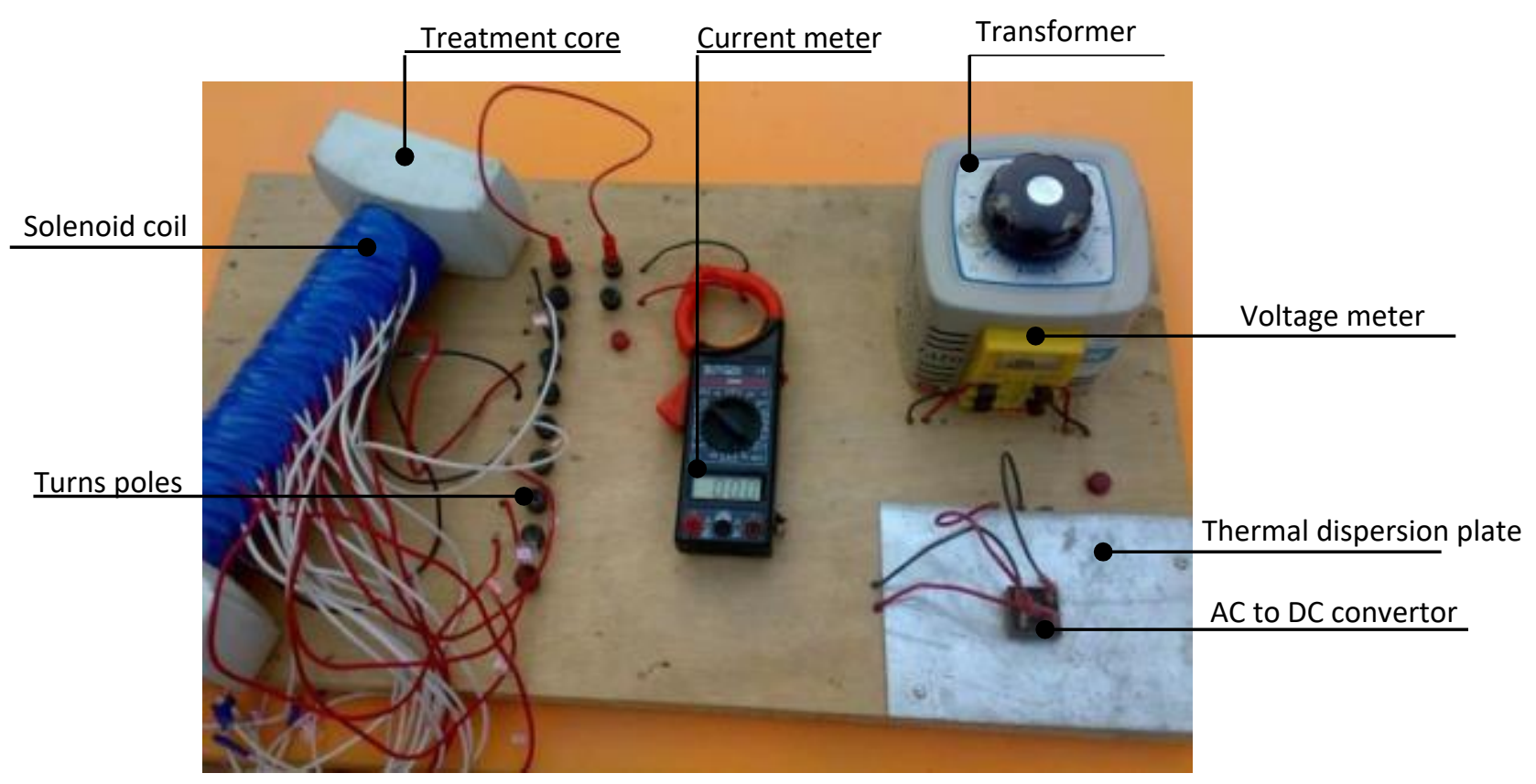

\section{Figure (2): The magnetic field generator}

This makes it more likely that the particles coagulate and that uncommon or unnecessary particles or pollutants can be removed. Hibben, 1973, [15] and Oshitani et al. 1999, [16] claimed that the effectiveness of a magnetic application ultimately depends not only on the magnetic strength but also on the magnetic gradient or magnetic flux concentration, which changes frequently along the magnetic device. Figure (4) shows two concrete particles, without and with magnetic treatment, the forces affecting the particle charge when magnetic field is applied in vertical direction. This force will separate the particle with positive solid and negative charge. The surface of the solid or liquid interface nucleus can be described as a surface characterized by a uniform charge density (Figure 4a). When an external vertical electric field is applied, the charge density is modified by a polarization effect, as shown in the schematic diagram in Figure (4b).

One of the best examples of magnetic applications is the Magnetic Resonance Imaging (MRI). (MRI) and it is used efficiently to examine the inside of the bodies with sufficient clarity. By applying static magnetic field to the human body which most contains water (more than $70 \%$ ) makes the water molecules distributed throughout our body in different ways and the MRI machine is able to see these differences and capture an image for the body. In the current study, a quit similar principle was developed and used to apply the necessary magnetic treatment to the fresh concrete while passing the fresh concrete thought out the treatment core. 


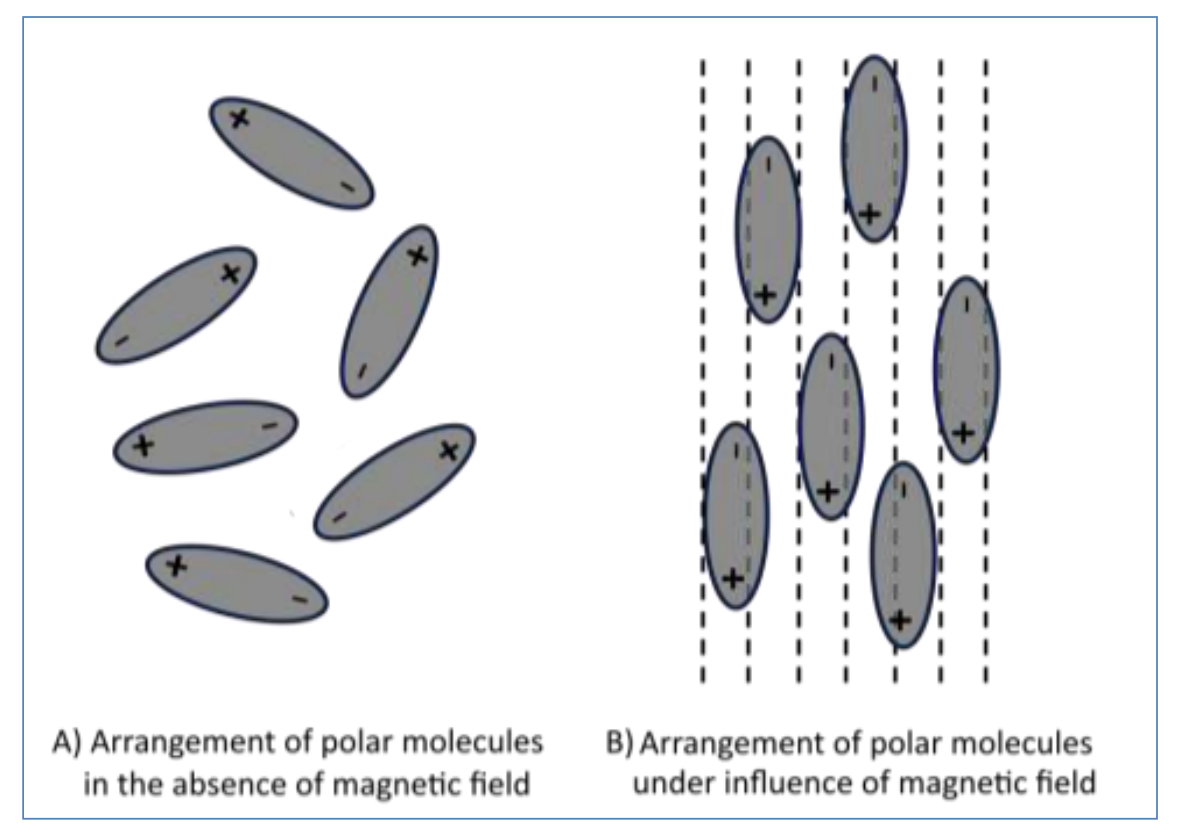

Figure (3): Molecules arrangement with and without magnetic field

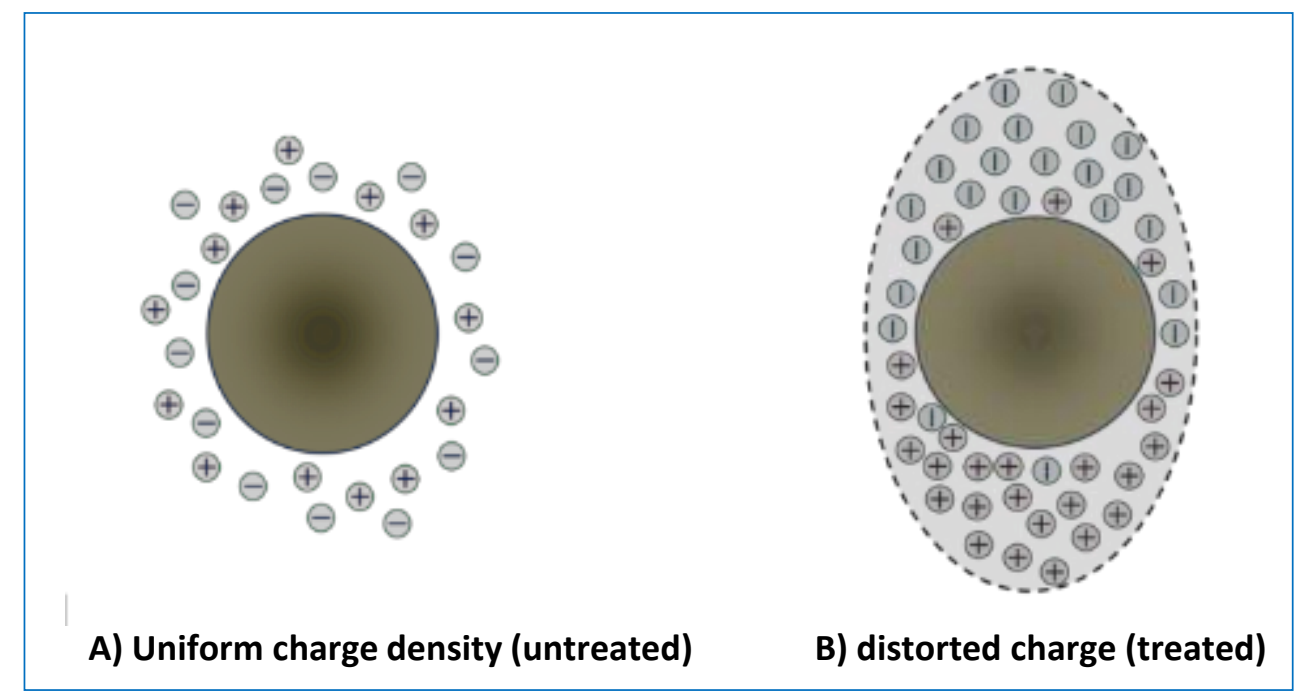

Figure (4): Ion charge particles (Beruto and Giordani, 1995)[17]

The MRI machine has a special coil of wire that is therefore the purposes of producing the needed magnetic energy to _irritate' the low energy hydrogen nuclei. The schematic diagram shows the basic components of the MRI machine, while passing the current 'I" magnetic field rapidly changing the diagram of water molecules in the body at the same time capturing $\mathrm{X}$ ray images [18]. 


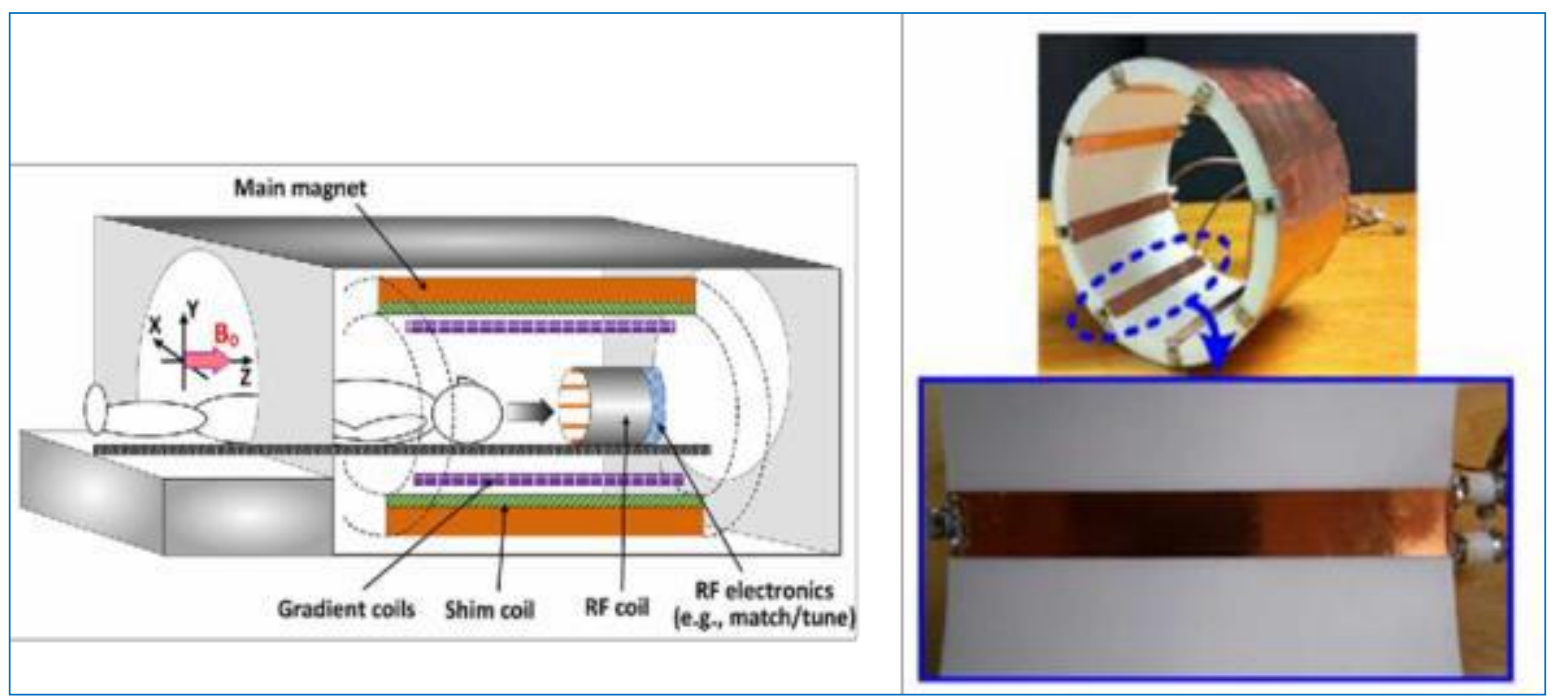

Figure (5): Structure illustration of a typical MRI scanner [18]

\section{Experimental Investigation}

\section{Materials:}

Ordinary Portland cement 'OPC' used in this research is according to ASTM specifications [19] with Grade 42.5. The chemical and physical properties of cement are provided in Tables (1) and (2), respectively [20-24].

Table (1): Chemical properties of Ordinary Portland Cement 'OPC'

\begin{tabular}{ccccccccc}
\hline $\mathrm{LOI}$ & $\mathrm{SiO}_{2}$ & $\mathrm{Al}_{2} \mathrm{O}_{3}$ & $\mathrm{Fe}_{2} \mathrm{O}_{3}$ & $\mathrm{CaO}$ & $\mathrm{MgO}$ & $\mathrm{SO}_{3}$ & $\mathrm{~K}_{2} \mathrm{O}$ & $\mathrm{Na}_{2} \mathrm{O}$ \\
\hline 3.87 & 21.7 & 4.8 & 3.08 & 60.2 & 2.85 & 2.43 & 0.62 & 0.45 \\
\hline
\end{tabular}

The fine aggregate used in this research is river sand (uncrushed) and the maximum size of fine aggregate is $4.75 \mathrm{~mm}$. Natural uncrushed gravel (local river gravel) is used as a coarse aggregate, It is well-graded and the maximum size is $20 \mathrm{~mm}$. Both of fine and coarse aggregate were grading within ASTM specifications. The physical properties of these aggregates are shown in Table (3) [25-31].

\section{Mix proportion}

In order to investigate the effect of different magnetic treatments on compressive strength and consistency of concrete, five batches are used, these batches are designated as N, MT1, MT2, MT3 and MT4; batch N is the untreated mix. While, batches MT1, MT2, MT3 and MT4 refers the concrete specimens which treated with constant magnetic intensities of $0.04,0.08$, 0.12 and $0.15 \mathrm{~T}$, respectively. All the specimens had similar mix proportion (1: $2.25: 1.85 / 0.36$ by weight) and the total weight of materials are as listed in Table (4). All samples are tested at the age of 7-days and 28-days. 
Table (2): Test method \& specifications of OPC cement (42.5 Grade)

\begin{tabular}{lccc}
\hline Component & Unit & Result & Standard \\
\hline Bulk Density & $\mathrm{kg} / \mathrm{m}^{3}$ & 0441 & ASTM C-188 \\
Normal Consistency & $\%$ & 24.00 & ASTM C-187 \\
Fineness & $\%$ & 59.01 & ASTM C-184 \\
Initial Setting Time & Mints & 90.11 & ASTM C-191 \\
Final Setting Time & Mints & 001.11 & ASTM C-191 \\
Soundness & Mm & 1.00 & BS 196-3 \\
\hline
\end{tabular}

Table (3): Physical properties of coarse and fine aggregate

\begin{tabular}{llccc}
\hline Aggregates & Component & Unit & Result & Standard \\
\hline \multirow{2}{*}{ Fine } & Bulk Density & $\mathrm{kg} / \mathrm{m}^{3}$ & 1650 & ASTM C-29 \\
& Fineness Modulus & - & 2.75 & ASTM C-136 \\
\cline { 2 - 5 } & Bulk Density & $\mathrm{kg} / \mathrm{m}^{3}$ & 0901 & ASTM C-29 \\
Coarse & Fineness modulus & -- & 3.2 & ASTM C-136 \\
& Water Absorption & $\%$ & 0.0 & ASTM C-127 \\
\hline
\end{tabular}

\section{Testing Of Specimens}

To find the effect of magnetic field on workability and compressive strength of fresh and hardened concrete, the concrete specimen's cubes were tested using the following tests:

Slump test

Slump test was conducted to measure the consistency of fresh concrete, to identify the effect of direct applying of static magnetic field on fresh concrete workability, the test carried out according to BS 1881: part 102:1983 requirements [32].

Concrete Compressive strength:

Prediction of compressive strength of concrete is very important since it affects other concrete properties. In this study compression test of concrete was conducted using Universal Testing Machine _UTM' by applying direct compression load to the concrete cube 
$(100 \times 100 \times 100 \mathrm{~mm})$ samples to determine the compressive strength capacity following EN12390-3:2001[33 ] requirements. The reported values represent the average results of three cube samples.

Table (4): Treatment levels to fresh concrete and mix proportions

\begin{tabular}{c|c|ccccccc}
\hline \multicolumn{2}{c}{ Specimen } & $\begin{array}{c}\text { Magnetic } \\
\text { flux } \\
\text { intensity } \\
(\mathbf{T})\end{array}$ & $\begin{array}{c}\text { Water/Cement } \\
\text { ratio }\end{array}$ & $\begin{array}{c}\text { Cement } \\
(\mathbf{k g})\end{array}$ & $\begin{array}{c}\text { Sand } \\
(\mathbf{k g})\end{array}$ & $\begin{array}{c}\text { Gravel } \\
(\mathbf{k g})\end{array}$ & $\begin{array}{c}\text { Water } \\
(\mathbf{k g})\end{array}$ & $\begin{array}{c}\text { Target } \\
\text { strength } \\
\left(\mathbf{N} / \mathbf{m m}^{2}\right)\end{array}$ \\
\hline Untreated & $\mathbf{N}$ & 1.1 & 0.36 & 450 & 1010 & 830 & 160 & 40 \\
\hline \multirow{5}{*}{ Treated } & MT1 & 0.04 & 0.36 & 450 & 1010 & 830 & 160 & 40 \\
\cline { 2 - 9 } & MT2 & 0.08 & 0.36 & 450 & 1010 & 830 & 160 & 40 \\
\cline { 2 - 9 } & MT3 & 0.12 & 0.36 & 450 & 1010 & 830 & 160 & 40 \\
\cline { 2 - 8 } & MT4 & 0.15 & 0.36 & 450 & 1010 & 830 & 160 & 40 \\
\hline
\end{tabular}

\section{Results and Discussion}

\section{Effect of magnetic field treatment on Consistency of concrete}

Experimental measurements for concrete workability for both treated and untreated mixes showed significant improvements in terms of horizontal and vertical slump magnitudes as presented in Table (5). In term of horizontal flow test, ratios of $D_{M}$ 'average diameter of settled fresh treated concrete in flow table test' to $\mathrm{D}_{\mathrm{N}}$ 'average diameter of settled fresh untreated concrete' were higher $74 \%, 81 \%, 78 \%$ and $59 \%$ corresponding to magnetic treatment intensity of $0.04,0.08,0.12$ and $0.15 \mathrm{~T}$, respectively. Table (4) explains utilizing of magnetic field treatments improves vertical slumps of concrete as compared to normal concrete. The measured slump for untreated mix was $350 \mathrm{~mm}$, unlikely it was $70 \%-91 \%$ higher in same mix after conducting magnetic treatment for fresh concrete. Furthermore, untreated batch did reach to a diameter of $500 \mathrm{~mm}$, while for treated mixes it was required a time of 8.1, 9.01, 5.74, and 10.4 second, respectively. Figure (6) compares the workability of treated and untreated mixes, the improvement in mix consistency due to magnetic treatment to the fresh concrete is quite clear.

The significant enhancement in fresh concrete consistency in treated mix was due surrounding the water partials all other mix components, and due to the presents of magnetic field which disperses cement partials from each other and generates hydration layers surrounding them, in addition to that magnetic field increases their molecular kinetic energy and with this increases the internal energy breaks and/or change some of the hydrogen bonds, resulting in more separate water molecules as shown in Figure (7). 
Table (5): Effect of magnetic field treatment on Consistency of concrete

\begin{tabular}{c|cccccc}
\hline Specimen & $\begin{array}{c}\text { Slump } \\
\text { diameter } \\
(\mathbf{m m})\end{array}$ & $\begin{array}{c}\mathbf{D}_{\text {average }} \\
(\mathbf{m m})\end{array}$ & $\mathbf{D}_{\mathbf{M}} \mathbf{\mathbf { D } _ { \mathbf { N } }}$ & $\begin{array}{c}* \mathbf{T 5 0 0} \\
(\mathbf{s e c})\end{array}$ & $\begin{array}{c}\text { Vertical Slump, S } \\
(\mathbf{m m})\end{array}$ & $\mathbf{S}_{\mathbf{M N}}^{\mathbf{S}}$ \\
\hline $\mathbf{N}$ & $301-300$ & 001 & - & --- & 350 & - \\
\hline MT1 & $600-730$ & 049 & 1.74 & 8.1 & 665 & 1.90 \\
MT2 & $650-690$ & 001 & 1.81 & 9.01 & 670 & 1.91 \\
MT3 & $650-670$ & 001 & 1.78 & 5.74 & 660 & 1.89 \\
MT4 & $560-620$ & 951 & 1.59 & 10.4 & 590 & 1.69 \\
\hline
\end{tabular}

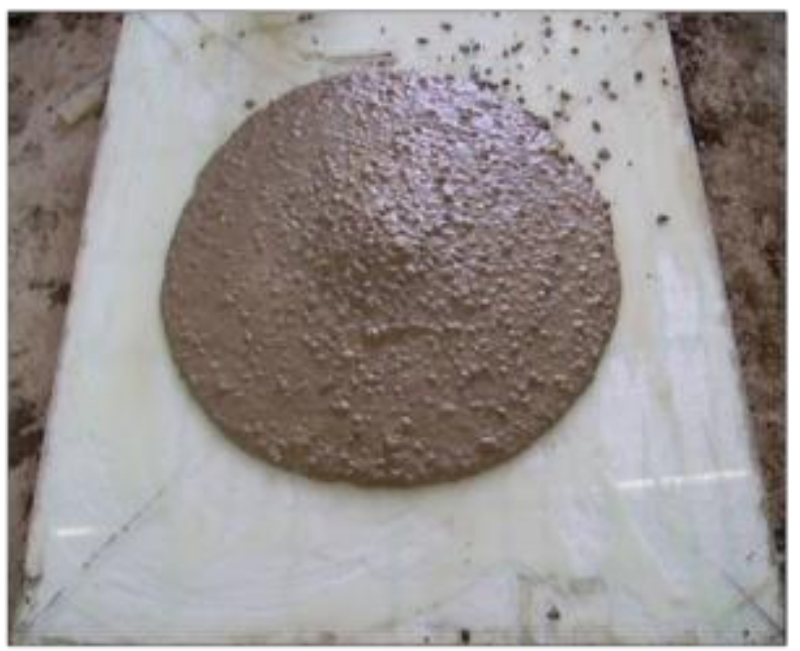

A) Treated fresh concrete (intensity 0.12T)

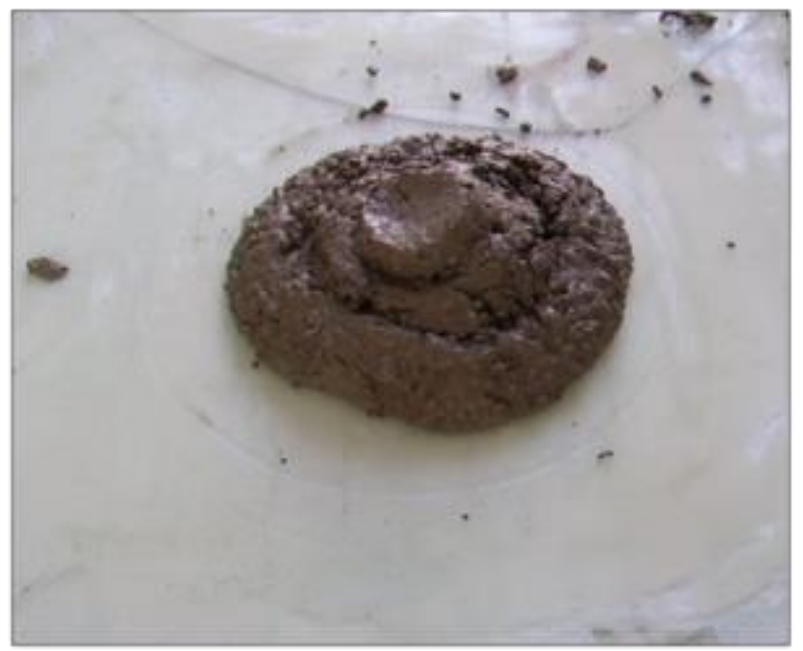

B) Untreated fresh concrete

Figure (6): Effect of magnetic fields on workability of concrete

\section{Effect of magnetic field treatment on concrete strength}

The results related to compressive strength showed that the compressive strength of specimens with magnetic field treatment were higher than that of the normal mix by $13 \%$, $15 \%, 19 \%$ and $4 \%$ corresponding magnetic field intensity treatment to fresh concrete of 0.04 , $0.08,0.12$ and $0.15 \mathrm{~T}$, respectively at 7 days age test as listed in Table (6). Unlikely, the magnetic treatment showed a lower strength increases at 28 days test and the relative increases in compressive strength for treated to untreated samples were higher in about $2 \%$, $5 \%$ and $14 \%$ corresponding magnetic field intensity treatment to fresh concrete of $0.04,0.08$ 


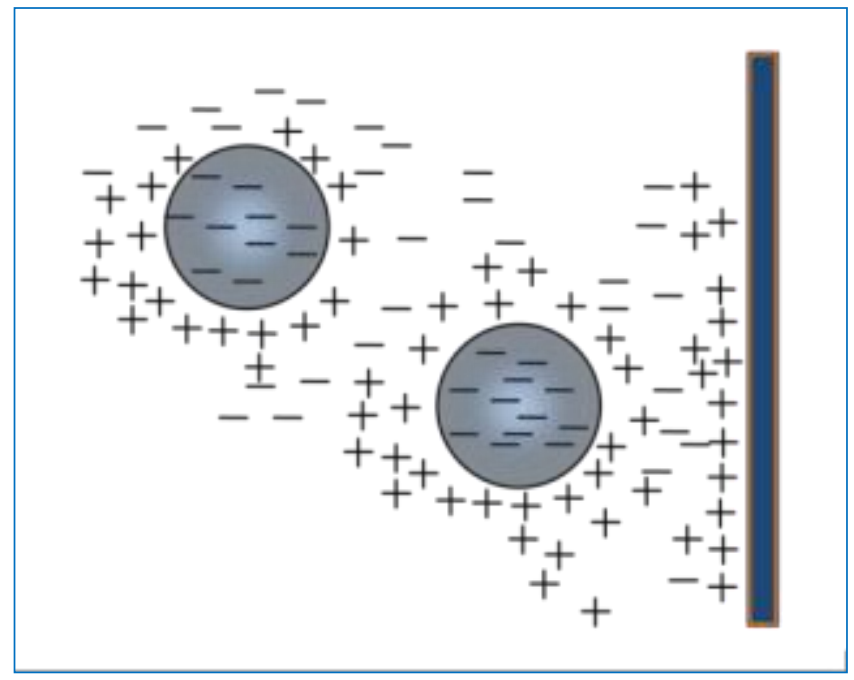

Figure (7): Enhanced surface charge on colloidal particles

and 0.12 , respectively. While the MT4 'magnetic field intensity of $0.15 \mathrm{~T}^{\prime}$ ' showed $2 \%$ lower

than untreated samples. Never the less, 7 days test showed also a marginal increase as compared to the other rang of treatment levels. Although the same mix proportions were used for all specimens, the increases in compressive strength were dominated on the flux density as shown in Figure (9). The magnetic flux intensity of $0.12 \mathrm{~T}$ 'MT3' proved the best result in term of strength performance for both 7 and 28 days tests among the rest of intensity treatments.

Table (6): Effect of magnetic field treatment on compressive strength of concrete

\begin{tabular}{|c|c|c|c|c|}
\hline Specimen & $\begin{array}{l}\text { Compressive } \\
\text { strength at } 7 \\
\text { days }\left(\mathbf{N} / \mathbf{m m}^{2}\right)\end{array}$ & $\begin{array}{c}\mathbf{f}_{\mathrm{cM}} / \mathbf{f}_{\mathrm{cN}} \\
\text { at } 7 \text { days }\end{array}$ & $\begin{array}{c}\text { Compressive strength at } \\
28 \text { days }\left(\mathrm{N} / \mathrm{mm}^{2}\right)\end{array}$ & $\begin{array}{c}\mathbf{f}_{\mathrm{cM}} / \mathbf{f}_{\mathrm{cN}} \\
\text { at } 28 \text { days }\end{array}$ \\
\hline $\mathbf{N}$ & 30.7 & - & 42.8 & - \\
\hline MT1 & 34.8 & 1.13 & 43.8 & 1.02 \\
\hline MT2 & 35.2 & 1.15 & 45.1 & 1.05 \\
\hline MT3 & 36.4 & 1.19 & 48.9 & 1.14 \\
\hline MT4 & 31.9 & 1.04 & 41.8 & 0.98 \\
\hline
\end{tabular}




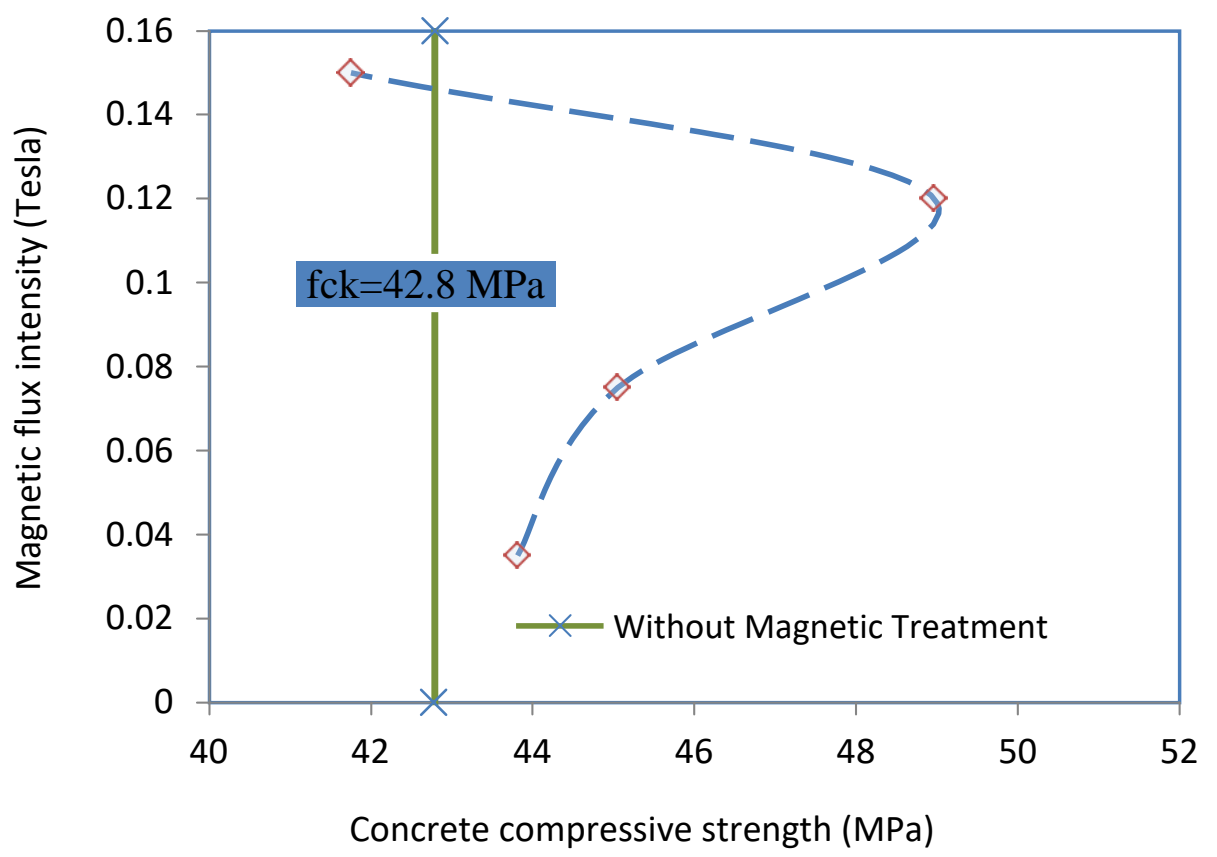

Figure (8): Behavior of concrete strength vs. various magnetic flux intensity

\section{treatments}

The microstructure of concrete materials showed that magnetic treatment to fresh concrete can strongly influence physical properties such as stronger bond of cement gel to filling materials and it showed surface of material as revealed without any cracks with a better interlocking, as presented in Figure (9).

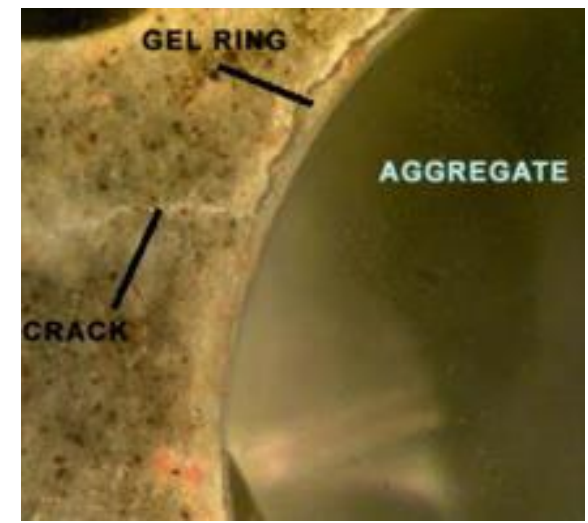

A) Un treated microstructure

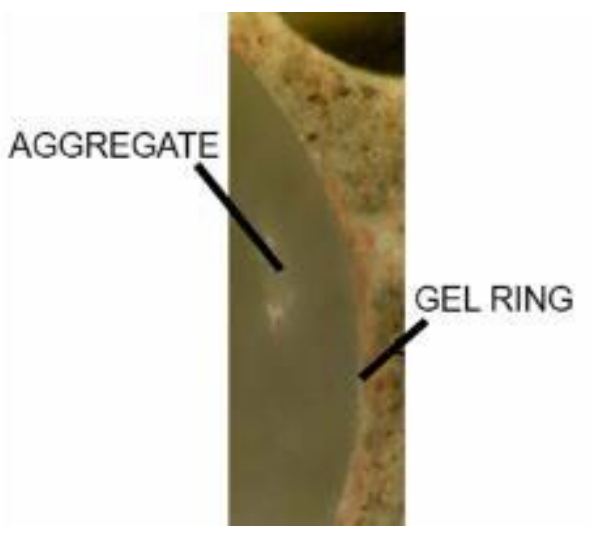

B) Treated microstructure

Figure (9): Comparison of microstructure of untreated and treated concrete mixes 


\section{Conclusions}

In the current study, a new technology of treated concrete prepared using the static magnetic field treatment was experimentally presented and investigated; this treatment is conducted by a device quite similar to MRI device. The effect of various magnetic treatments $(0,0.04$, $0.08,0.12$ and 0.15 Tesla) to the fresh and hard concrete characteristics was quantified. Methodology of the current proposal is to manipulate the placing process of the fresh concrete samples, while maintaining the same materials with the same other configurations. Results showed that directly applying magnetic field on concrete could increase the compressive strength in about 4-19\%, simultaneously the flow showed significant improvements. Magnetic treatments of 0.08 and 0.12 Tesla for fresh concrete mix showed a better flow ability with higher increases in concrete strength as compared to other range of magnetic treatments. Unlike, the magnetic treatments could be detrimental for some other range of treatments especially at long-term performance in terms of strength $(0.15 \mathrm{~T}$ treatment rang), however but not in flow. These enhancements in the mechanical properties of concrete was due to enhancement the microstructure of concrete materials magnetic fields disperses cement particles from hydration layers surrounding the filling particles, at the same time increases their molecular internal energy to breaks and/or change some of the hydrogen bonds, resulting in more separate water molecules. However, the results could become a base for further studies aims to construction of a new generation of smart materials with unique property.

\section{References}

[1] S. Ahmed, - Effect of magnetic water on engineering properties of concretell, Journal of Al-Rafidain Eng., vol.17, no. 1, (2009), pp.71-82.

[2] I. Abavisani, O. Rezaifar, A. Kheyroddin, -Magneto-Electric control of scaled-down reinforced concrete beams\|, Journal ACI Stru., vol. 114, no.1, (2009), pp. 233-244.

[3] S. Nan, W. Chea-Fang,. - Effect of Magnetic Field Treated Water on Mortar and Concrete containing Fly Ashll, J.Cem. \& Conc. Comp., vol. ,no.7, (2003), pp. 681-688.

[4] H. Afshin, M. Gholizadeh, N. KhorshidIi, -Improving mechanical properties of high strength concrete by magnetic water technologyll, Scientia Iranica, vol.1 (2010), pp. 74-79.

[5] Y. R Tawfic, W. Abdelmoez, ॥, The Influence of Water Magnetization on Fresh and Hardened Concrete Properties\|, International J. of Civil Eng. and Technology, vol.(6) (2013),pp. 31-43.

[6] M. Gholizadeh, H. Arabshahi, - The effect of magnetic water on strength parameters of concretell, J.1 of Eng. and Technology Research vol.3 (2011), pp.77-81. 
[7] B. S. K Reddy, V. G Ghorpade, H. S. Rao, - Effect of Magnetic Field Exposure Time on Workability and Compressive Strength of Magnetic Water Concretel, International J. of Advances in Eng. and Tech., vol.3 (2013),pp. 120-122.

[8] R. Cai, H. Yang, J. He, W. Zhu, - The Effects of Magnetic Fields on Water Molecular Hydrogen Bondsl, J. of Molecular Struc., 938(1-3) (2009),pp. 15-19.

[9] A. R Soltani Todeshki, H. Raeisi Vanani, M. Shayannejad, K. Ostad Ali Askari, - Effects of Magnetized Municipal Effluent on Some Chemical Properties of Soil in Furrow Irrigation, International J. of Agriculture and Crop Sciences, vol.8, no. 3, (2015), pp. 482-489.

[10] N. Su, Y. H. Wu, C. Y. Mar, - Effect of Magnetic Water on the Engineering Properties of Concrete Containing Granulated Blast-Furnace Slag\|, Cem. and Con.e Research, vol.30, no.4 (2000), pp.599-605.

[11] A. Iman, R Omid, K. Ali, - Magneto-Electric Control of Scaled-Down Reinforced Concrete Beams\|, ACI Struc. J. 114, (1) (2017),pp. 1-11.

[12] A. Khamees, k. Khaldon , K. Ahmed, - Properties of concrete with magnetic mixing waterl, IP Conference Proceedings 2213, 020146 (2020); https://doi.org/10.1063/5.0000330.

J. R., Reitz, - Foundations of Electromagnetic Theoryll,ddison-Wesley Publishing Company, Inc.

Philippines, 2nd Additio(1971).

[14] E. R., Dobbs, -Electricity and Magnetismll, Routledge \& Kegan Paul, London, (1984).

[15] S.G. Hibben,-Magnetic Treatment of Eaterll; Air Force Office of ScientificResearch, Advance Research Projects Agency: Arlington, VA (1973).

[16] J. Oshitani, D. Yamada, M. Miyahara, K. Higashitani, - Magneticeffects on ion exchange kinetics\|, J. Coll. Int. Sci., 210 (1999),pp. 1-7.

[1] D.T. Beruto, M. Giordani, - Effects of low frequency electromagnetic fields on crystal growth from solution. In: Compton, R.G. and Hancock, G. Research in Chemical Kinetics, Elsevier Science. Vol.3 (1995): pp 175.

[18] S. Sung-Min, D. Lance, G. Anand, J. Thomas Vaughan, - RF Head Coil Design With Improved RF Magnetic Near-Fields Uniformity for Magnetic Resonance Imaging (MRI) Systems\|, IEEE Transactions on Microwave Theory and Techniques.vol. 62,no. 8 Aug. (2014).

[19] ASTM C150-07, - Standard Specification for Portland Cement; American Society for Testing and Materials\|: West Conshohocken, PA, USA, (2007).

[20] ASTM C114-06, - Standard Test Methods for Chemical Analysis of Hydraulic Cement; American Society for Testing of Materials\|: Philadelphia, PA, USA, (2004). 
[21] ASTM C187-98, - Standard Test Method for Normal Consistency of Hydraulic Cement; Annual Book of ASTM Standards, American Society for Testing and Materiall: West Conshohocken, PA, USA,( 2002).

[2] ASTM C191-13, - Standard Test Methods for Time of Setting of Hydraulic Cement by; VicatNeedle ASTM International: West Conshohocken, PA, USA, (2013). ASTM C188-17, - Standard Test Method for Density of Hydraulic Cement; American Society for Testing and Materialll: West Conshohocken, PA, USA, (2009). BSI, BS EN 196-3, - Methods of Testing Cement-Part 3: Determination of Setting Times and Soundnessl; British Standards Institution: London, UK, (2005). ASTM C136-01, - Standard Test Method for Sieve Analysis of Fine and Coarse Aggregates\|; Annual Book of Standards, American Society for Testing and Material: West Conshohocken, PA, USA, (2002). ASTM C33/C33M-11a, - Standard Specification for Concrete Aggregates; American Society for Testing and Materiall: West Conshohocken, PA, USA,( 2004); pp. 1-11.

[2] ASTM C29/C29M-07, - Standard Test Method for Bulk Density (Unit Weight) and Voids in Aggregatell; ASTM International: West Conshohocken, PA, USA, 2007.

BSI B812-112,. Testing Aggregates. - Method for Determination of Aggregate Impact Value (AIV) ॥; British Standards Institution: London, UK, (1990). BSI B812-110:1990. - Testing Aggregates-Methods for Determination of Aggregate Crushing Value $(\mathrm{ACV}) \|$; British Standards Institution: London, UK, (1990).

[30] ASTM C131/C131M. - Standard Test Method for Resistance to Degradation of Small-Size Coarse Aggregate by Abrasion and Impact in the Los Angeles Machinel; ASTM: West Conshohocken, PA, USA, (2008).

[31] ASTM C128-15, - Standard Test Method for Relative Density (Specific Gravity) and Absorption of Coarse Aggregatell, ASTM: West Conshohocken, PA, USA, (2015).

[32] BS 1881-108, - Method for making Test Cubes from Fresh Concretl, BSI- British Standards Institution, London, (1983).

[33] EN 12390-5, - Testing hardened concrete. Flexural strength of test specimens\|, BSI- British Standards Institution, London, ( 2009). 